\title{
KONSEP DIRI IBU DAN REMAJA PADA KELUARGA CERAI DAN UTUH
}

\author{
Lisnani Sukaidawati $^{*}$, Diah Krisnatuti ${ }^{2}$, Ratna Megawangi ${ }^{2}$ \\ 1Yayasan Kita dan Buah Hati, Jl. Jatayu Raya Bok F 6 No. 21 Jatibening Estate, Bekasi 17412, Indonesia \\ 2Departemen IImu Keluarga dan Konsumen, Fakultas Ekologi Manusia, Institut Pertanian Bogor,
} Bogor 16680, Indonesia

*)E-mail: lisna_rumahparenting@yahoo.com

\begin{abstract}
Abstrak
Studi ini bertujuan untuk menganalisis pengaruh karakteristik keluarga, karakteristik remaja, dan konsep diri ibu terhadap konsep diri remaja pada keluarga cerai dan utuh. Populasi penelitian ini adalah remaja yang berusia 12-14 tahun yang tinggal bersama ibu. Contoh diambil dari 3 SMP di Kecamatan Bogor Barat dan 3 SMP di Kecamatan Tanah Sareal, Kota Bogor. Penarikan contoh remaja dari keluarga cerai menggunakan teknik purposive sampling. Contoh yang berhasil dikumpulkan dan memenuhi syarat sebanyak 79 siswa dari seluruh siswa kelas VII dan VIII. Sementara itu, penarikan contoh remaja keluarga utuh menggunakan teknik random sampling berdasarkan daftar nama siswa dan kelas yang ada di masing-masing sekolah. Jumlah contoh yang diperlukan sama dengan jumlah contoh yang berhasil dikumpulkan pada remaja keluarga cerai yaitu sebanyak 79 siswa sehingga penelitian ini melibatkan 158 siswa remaja dan 158 ibunya. Hasil menunjukkan bahwa konsep diri remaja secara signifikan dipengaruhi oleh konsep diri ibu pada dimensi spiritual, kejujuran, akademik, stabilitas emosi, dan penampilan fisik. Sementara itu, usia remaja, status perkawinan ibu, usia ibu, pekerjaan ibu, dan pendapatan keluarga tidak berpengaruh terhadap konsep diri remaja.
\end{abstract}

Kata kunci: keluarga cerai, keluarga utuh, konsep diri ibu, konsep diri remaja

\section{Self-Concept of Mother and Adolescent at Divorce and Intact Family}

\begin{abstract}
This study aimed to analyze the influence of family characteristics, characteristics of teenager, and self-concept of mother on self-concept of teenager in divorce and intact family. Population of this study was teenager with aged 12-14 years old who lived with their mother. Samples were taken from three secondary schools in the District of West Bogor and three junior high schools in the District of Tanah Sareal, Bogor City. Sampling of teenagers from divorce families was using purposive sampling technique. Collected and qualified samples were 79 students from all students of class VII and VIII. Meanwhile, sampling of teenager from intact families was using random sampling techniques based on a list of names of students and classes that exist in each school. The number of samples required is equal to the amount of sample collected on teenager of divorce family as many as 79 students, so this study involving 158 teenager students and 158 mothers of teenager students. The results indicate that the adolescent self-concept was significantly influenced by mother self-concept on the spiritual dimension, honesty, academic, emotional stability, and physical appearance. Meanwhile, the teen age, marital status, mother's age, mother's occupation, and family income has no effect on adolescent self-concept.
\end{abstract}

Keywords: divorce family, intact family, maternal self-concept, self-concept teen

\section{PENDAHULUAN}

Perceraian di Indonesia saat ini mengalami peningkatan secara drastis sejak tahun 2001. Data Badan Urusan Peradilan Agama tahun 2010 mencatat bahwa selama periode 2005 hingga 2009 telah terjadi peningkatan jumlah perceraian setiap tahunnya. Hasil dari berbagai penelitian menunjukkan bahwa perceraian memiliki dampak yang merugikan bagi perkembangan anak dan remaja. Penelitian yang dilakukan oleh Barber dan Eccles (1992) menerangkan bahwa remaja dari keluarga cerai cenderung memiliki kesulitan belajar sehingga nilai yang dicapai di sekolah menjadi rendah. Adapun hasil metaanalisis konsekuensi pada keluarga cerai yang dilakukan oleh Amato (2000) menemukan fakta bahwa anak dari keluarga cerai rendah dalam hal pencapaian akademik, tingkah laku, penyesuaian psikologis, konsep diri, dan kompetensi sosial. Pernyataan tersebut memperkuat hasil penelitian yang dilakukan oleh Nye (1957), yang diacu dalam Pryor dan Rodgers (2001) juga menemukan bahwa anak yang berasal dari keluarga cerai memiliki nilai sekolah yang lebih rendah dibandingkan dengan anak dari keluarga utuh. Hasil penelitian lain menyatakan bahwa anak 
dari keluarga cerai lebih cenderung putus sekolah (Evans et al., 2001), dan lebih cenderung mengalami kecemasan, kesepian, memiliki harga diri yang rendah, serta kesedihan (Kim, 2011).

Memang tidak semua dampak negatif perceraian ada pada semua keluarga yang mengalami perceraian. Beberapa keluarga yang telah melewati fase krisis cenderung merasa lebih kuat. Pengalaman mengalami perceraian memang menyakitkan bagi anggota keluarga, tetapi terkadang keputusan berpisah harus diambil untuk memungkinkan keluarga terus bertumbuh ke arah yang lebih produktif. Tinggal di keluarga utuh dengan konflik yang tinggi dan terus menerus juga juga tidak menguntungkan bagi anak. Penelitian lain menyatakan bahwa anak-anak yang tinggal di keluarga utuh dengan konflik yang tinggi cenderung menunjukkan akademik yang rendah, dibandingkan dengan anak-anak yang tinggal bersama single parent dan ayah tiri. Hal ini memungkinkan anak-anak merasa lebih kuat dan nyaman secara psikologis (Musick \& Meier, 2010).

Kondisi remaja dengan ibu tunggal berbedabeda, bergantung pada gender dan struktur keluarga, hubungan ibu dan remaja serta pengalaman hidup dalam keluarga. Remaja perempuan cenderung memiliki persepsi lebih positif dalam hal penerimaan ibu, dan kekompakkan karena berkurangnya tekanan terhadap disiplin dibandingkan remaja laki-laki. Sebaliknya remaja dari keluarga utuh cenderung memiliki persepsi ibu kurang memiliki kontrol, posesif, cemas, bebas, menunjukkan dominasi dan lebih asertif. Berbagai hasil penelitian tentang dampak perceraian pada ibu menjelaskan bahwa setelah perceraian, ibu mengalami penyusutan sumber daya penting dalam melakukan fungsi pengasuhan, yaitu hilangnya dukungan psikologis dan ekonomi dari pasangan, perubahan status, peran, dan krisis identitas, gangguan emosi (Amato, 2000), kesepian, merasa tak berdaya, tak memiliki harapan, dan kehilangan rasa percaya diri (Kotwal \& Prabhakar, 2009). Penyusutan dari berbagai aspek tersebut menempatkan ibu pada posisi dan situasi dengan level stres yang tinggi (Hamid \& Salleh, 2013) dan gangguan konsep diri. Kondisi stres yang terus menerus dapat memengaruhi konsep diri ibu.

Dampak perceraian pada ibu juga berbeda tergantung tipe kepribadian ibu. Ibu dengan ciriciri kepribadian ektraversi dan terbuka cenderung memiliki level stres yang rendah (Fani \& Kheirabadi, 2011). Sebaliknya, ketidakmampuan ibu dalam menanggulangi sumber stress dapat memengaruhi kemampuan ibu dalam melakukan adaptasi dengan situasi dan kondisi selama dan setelah perceraian. Pada keluarga single parent, orang tua menjadi sumber daya penting bagi anak. Ibu menjadi satu-satunya sumber daya yang dimiliki oleh anak. Gangguan konsep diri ibu yang disebabkan oleh kondisi stress sebelum, selama, dan sesudah perceraian dapat memengaruhi konsep diri remaja.

Remaja merupakan aset sumber daya manusia yang penting dalam kemajuan dan kemunduran suatu bangsa. Berdasarkan data BPS (2012) populasi remaja di Indonesia mencapai 26,5 persen dari total penduduk Indonesia, atau sekitar 64 juta jiwa. Jumlah tersebut cukup besar, karena itu diperlukan perhatian yang serius terkait penanganan perkembangan dan permasalahan yang menyertai tumbuh kembang remaja, baik secara fisik, psikologis maupun sosial. Selain itu, pada masa remaja sedang terjadi perubahan-perubahan fisik yang cepat, disertai adanya peralihan dari masa kanak-kanak menuju masa dewasa, sehingga remaja harus mempersiapkan diri dan melakukan penyesuaian mental untuk menghadapinya (Hurlock, 1980).

Konsep diri merupakan salah satu aspek yang penting dalam perkembangan remaja. Menurut Rakhmat (2011) konsep diri adalah persepsi fisik, sosial, dan psikologis tentang diri individu yang berasal dari pengalaman-pegalaman dan interaksi dengan orang lain. Konsep diri terbentuk dari hasil belajar atau pengalaman seseorang dalam berinteraksi dengan orangorang di sekitarnya. Orang-orang yang paling dekat dan pertama kali dikenal oleh remaja sejak masa kanak-kanak adalah keluarga, sehingga keluarga memiliki peran penting dalam membentuk konsep diri remaja. Dalam menjalani proses tumbuh kembang remaja, konsep diri akan menentukan dan mengarahkan perilaku remaja selanjutnya. Kajian mengenai konsep diri remaja sering dihubungkan dengan pencapaian akademik (Liu, 2009; Sagone \& Carolli, 2014) dan pengasuhan (Devi et al., 2013).

Berdasarkan pemaparan tersebut dapat disusun sebuah hipotesis bahwa remaja dari keluarga cerai cenderung memiliki konsep diri lebih negatif dibandingkan remaja yang berasal dari keluarga utuh. lbu yang mengalami perceraian juga cenderung akan memiliki konsep diri yang lebih negatif dibandingkan ibu dari keluarga utuh. Kuat dugaan bahwa konsep diri ibu berpengaruh positif terhadap konsep diri remaja. Sayangnya penellitian-penelitian yang sudah ada tidak menghubungkan dan/atau meneliti pengaruh konsep diri ibu terhadap konsep diri remaja 
sehingga tidak dapat diketahui apakah konsep diri ibu yang mengalami perceraian keluarga memberikan kontribusi pengaruh pada konsep diri remaja. Selain itu penelitian yang memfokuskan pada hubungan konsep diri ibu dengan konsep diri remaja masih terbatas (Esmaeili \& Yacoob, 2012), khususnya pada remaja dari keluarga cerai dan utuh. Oleh karena itu, penting dilakukan penelitian untuk menganalisis pengaruh konsep diri ibu terhadap konsep diri remaja pada keluarga cerai dan utuh.

Penelitian ini bertujuan untuk menganalisis perbedaan karakteristik remaja, karakteristik keluarga, konsep diri ibu, dan konsep diri remaja pada keluarga cerai dan utuh. Selain itu, penelitian juga dilakukan untuk menganalisis hubungan antarvariabel penelitian, serta untuk menganalisis pengaruh karakteristik remaja, karakteristik keluarga, dan konsep diri ibu terhadap konsep diri remaja yang berasal dari keluarga cerai dan keluarga utuh.

\section{METODE}

Penelitian ini menggunakan desain cross sectional dengan metode survei. Pengambilan data dilakukan di Kota Bogor, Provinsi Jawa Barat. Penelitian dilakukan pada bulan Juli sampai dengan Desember tahun 2013. Populasi penelitian ini adalah remaja yang berusia 12-14 tahun yang tinggal bersama ibu. Contoh diambil dari 3 SMP di Kecamatan Bogor Barat dan 3 SMP lainnya di Kecamatan Tanah Sareal. Penarikan contoh remaja dari keluarga cerai menggunakan teknik purposive sampling. Contoh yang berhasil dikumpulkan dan memenuhi syarat sebanyak 79 orang dari seluruh siswa kelas VII dan VIII. Sementara itu penarikan contoh remaja keluarga utuh menggunakan teknik random sampling berdasarkan daftar nama siswa dan kelas yang ada di masing-masing sekolah. Dengan demikian, total contoh dalam penelitian ini berjumlah 158 orang, terdiri atas 79 orang remaja dari keluarga cerai dan 79 orang remaja dari keluarga utuh.

Data yang dikumpulkan meliputi data primer dan sekunder. Data primer dalam penelitian ini terdiri atas karakteristik remaja, karakteristik keluarga, konsep diri ibu, dan konsep diri remaja. Sedangkan data sekunder berupa data-data pendukung yang diperoleh dari sekolah, kantor Diknas setempat, dan kantor Pengadilan Tinggi Agama Kota Bogor. Pengumpulan data primer dilakukan dengan pengisian kuesioner melalui wawancara. Karakteristik remaja terdiri atas usia dan jenis kelamin. Karakteristik keluarga meliputi usia ibu, pendidikan ibu, pekerjaan ibu, dan pendapatan keluarga.

Konsep diri ibu diukur dengan menggunakan instrumen yang dikembangkan oleh Marsh (1992) yaitu Self Description Questionaire (SDQ) III yang terdiri atas 66 pernyataan dengan nilai Cronbach's alpha sebesar 0,864. Penilaian pada konsep diri ibu dilihat dari 13 dimensi yaitu matematika, spiritual, kejujuran, relasi lawan jenis, akademis, pemecahan masalah, kemampuan fisik, penilaian keseluruhan diri (general self), verbal, stabilitas emosi, relasi orang tua, penampilan fisik, dan relasi teman berjenis kelamin sama (Marsh, 1992). Sementara itu, konsep diri remaja diukur dengan menggunakan instrumen yang dikembangkan oleh Marsh (1992) untuk mengukur konsep diri remaja yaitu Self Description Questionaire (SDQ) II). Kuesioner terdiri atas 39 pernyataan (nilai Cronbach's alpha sebesar 0,911). Penilaian pada konsep diri remaja dilihat dari 10 dimensi yang terdiri atas dimensi matematika, penampilan fisik, penilaian keseluruhan diri, kejujuran, kemampuan fisik, verbal, relasi teman sebaya, relasi orang tua, sekolah, dan relasi lawan jenis.

Instrumen SDQ telah digunakan secara luas di berbagai negara, dan sudah diterjemahkan ke dalam 20 bahasa, termasuk diantaranya digunakan dalam National Education Longitudinal Survey di 1000 SMA di AS; Proyek Model Sekolah Nasional dan Head Start Program; studi untuk mengukur pencapaian hasil sekolah di negara-negara yang tergabung dalam OECD; dan evaluasi nasional Sekolah Lanjutan Atas di Hongkong. Bahkan menurut Hattie (1992) yang diacu oleh Craven dan Marsh (2008) instrumen SDQ sebagai sebuah rangkaian pengukuran terbaik yang tersedia saat ini karena memiliki item yang sensitif untuk mengukur konsep diri sebagai sebuah konsep yang multidimensi.

Selama ini pengukuran konsep diri pada ibu dan anak dilakukan dengan instrumen yang berbeda. Kelebihan instrumen penelitian ini adalah, konsep diri diukur dengan instrumen yang sama pada ibu dan anak, sehingga akan terlihat hubungan masing-masing dimensi pada konsep diri ibu dan anak. Namun demikian, terdapat kelemahan pada pengukuran dimensi konsep diri akademik yang terlalu fokus pada matematika. Oleh karena itu, peneliti mencoba memasukkan semua dimensi sebagai satu set kesatuan instrumen dengan tujuan untuk melihat konsistensi hubungan antar dimensi. 
Selanjutnya skor total setiap dimensi diperoleh dengan menjumlahkan total jawaban. Skor total ditransformasikan ke dalam bentuk indeks, lalu dikategorikan menjadi dua kategori yaitu konsep diri negatif $(0,0-60,0)$ dan konsep diri positif $(61,0-100,0)$. Setelah itu data dianalisis dengan menggunakan uji beda $t$, uji korelasi, dan uji regresi linear berganda. Uji beda $t$ dilakukan untuk menganalisis perbedaan karakteristik remaja, karakteristik keluarga, konsep diri ibu, dan konsep diri remaja antara keluarga cerai dan utuh. Sementara itu, uji korelasi dilakukan untuk menganalisis hubungan antarvariabel penelitian, dan uji regresi linear berganda dilakukan untuk menganalisis pengaruh karakteristik remaja, karakteristik keluarga, dan konsep diri ibu terhadap konsep diri remaja.

\section{HASIL}

\section{Karakteristik Remaja dan Keluarga}

Berdasarkan hasil analisis, usia remaja, usia ibu, dan pendapatan keluarga (Rp/kapita/bulan) antara keluarga cerai dan utuh berbeda signifikan $(p<0,01)$. Rata-rata usia remaja pada keluarga cerai (13,5 tahun) lebih tinggi dibandingkan dengan rata-rata usia remaja pada keluarga utuh (12,5 tahun). Rata-rata usia ibu pada keluarga cerai $(42,6$ tahun) juga lebih tinggi dibandingkan dengan keluarga utuh $(39,9$ tahun). Akan tetapi, rata-rata pendapatan keluarga per kapita per bulan pada keluarga utuh lebih besar dibandingkan dengan keluarga cerai.

Berkaitan dengan pendidikan ibu dan besar keluarga, baik pada keluarga cerai dan keluarga utuh tidak berbeda signifikan. Berdasarkan status pekerjaan ibu, sebanyak 73,4 persen pada keluarga cerai adalah ibu bekerja, sedangkan pada keluarga utuh, sebanyak 62,0 persen adalah ibu rumah tangga.

\section{Konsep Diri Remaja}

Lebih dari tiga perempat remaja yang berasal dari keluarga cerai $(79,7 \%)$ dan keluarga utuh $(77,2 \%)$ memiliki konsep diri total yang positif (Tabel 1). Persentase tertinggi konsep diri remaja dengan kategori positif pada keluarga cerai $(91,1 \%)$ dan pada keluarga utuh $(92,4 \%)$ terdapat pada dimensi relasi orang tua. Remaja menilai bahwa hubungannya dengan orang tua seperti melakukan aktivitas bercakap-cakap, menghabiskan waktu bersama dan melakukan aktifitas bersama sudah baik. Sebagian besar remaja $(>80,0 \%)$ dari keluarga utuh dan keluarga cerai memiliki konsep diri positif pada dimensi kejujuran.
Tabel 1 Sebaran responden berdasarkan konsep diri remaja pada keluarga cerai dan utuh

\begin{tabular}{|c|c|c|c|c|}
\hline \multirow[t]{2}{*}{ Dimensi } & \multicolumn{2}{|c|}{$\begin{array}{l}\text { Keluarga Cerai } \\
(\%)\end{array}$} & \multicolumn{2}{|c|}{$\begin{array}{c}\text { Keluarga Utuh } \\
(\%)\end{array}$} \\
\hline & + & - & + & - \\
\hline Matematika & 32,9 & 67,1 & 40,5 & 59,5 \\
\hline Penampilan fisik & 59,5 & 40,5 & 59,5 & 40,5 \\
\hline $\begin{array}{l}\text { Penilaian } \\
\text { keselluruhan diri }\end{array}$ & 29,1 & 70,9 & 73,4 & 26,6 \\
\hline Kejujuran & 82,3 & 17,7 & 81,0 & 19,0 \\
\hline Kemampuan fisik & 38,0 & 62,0 & 40,5 & 59,5 \\
\hline Verbal & 46,8 & 53,2 & 44,3 & 55,7 \\
\hline $\begin{array}{l}\text { Relasi teman } \\
\text { sebaya }\end{array}$ & 65,8 & 34,2 & 51,9 & 48,1 \\
\hline Relasi orang tua & 91,1 & 8,9 & 92,4 & 7,6 \\
\hline Sekolah & 68,4 & 31,6 & 63,3 & 36,7 \\
\hline Relasi lawan jenis & 62,0 & 38,0 & 51,9 & 48,1 \\
\hline Konsep diri total & 79,7 & 20,3 & 77,2 & 22,8 \\
\hline
\end{tabular}

Persentase tertinggi dengan kategori negatif pada hampir tiga perempat remaja dari keluarga cerai $(70,9 \%)$ terdapat pada dimensi penilaian keseluruhan diri. Dimensi keseluruhan diri adalah penilaian remaja terhadap kapasitas diri yang menimbulkan kebanggaan dan kepuasan dalam menampilkan diri apa adanya. Sementara itu, pada keluarga utuh persentase tertinggi untuk konsep diri remaja yang negatif adalah dimensi matematika (59,5\%). Dimensi matematika adalah penilaian remaja terhadap kemampuan dan keahliannya dalam bidang matematika. Selanjutnya hasil uji beda $t$ yang tersaji pada Tabel 2 menunjukkan bahwa konsep diri remaja untuk semua dimensi dan konsep diri total pada keluarga bercerai maupun keluarga utuh tidak berbeda signifikan.

Tabel 2 Hasil uji beda konsep diri remaja pada keluarga cerai dan utuh

\begin{tabular}{|c|c|c|c|}
\hline Dimensi & $\begin{array}{c}\text { Rata-rata } \\
\text { Keluarga } \\
\text { Cerai }\end{array}$ & $\begin{array}{c}\text { Rata-rata } \\
\text { Keluarga } \\
\text { Utuh }\end{array}$ & $p$-value \\
\hline Matematika & 55,27 & 54,54 & 0,843 \\
\hline Penampilan fisik & 66,56 & 67,37 & 0,792 \\
\hline $\begin{array}{l}\text { Penyeseuaian } \\
\text { keseluruhan diri }\end{array}$ & 69,90 & 71,03 & 0,719 \\
\hline Kejujuran & 79,91 & 76,27 & 0,175 \\
\hline Kemampuan fisik & 56,65 & 55,17 & 0,688 \\
\hline Verbal & 61,92 & 59,77 & 0,497 \\
\hline $\begin{array}{l}\text { Relasi teman } \\
\text { sebaya }\end{array}$ & 65,96 & 63,36 & 0,418 \\
\hline Relasi Orang tua & 85,86 & 86,36 & 0,842 \\
\hline Sekolah & 65,82 & 63,61 & 0,523 \\
\hline $\begin{array}{l}\text { Relasi Lawan } \\
\text { Jenis }\end{array}$ & 67,83 & 63,45 & 0,141 \\
\hline Konsep diri total & 68,89 & 67,46 & 0,346 \\
\hline
\end{tabular}




\section{Konsep Diri lbu}

Lebih dari separuh ibu yang berasal dari keluarga cerai $(53,2 \%)$ memiliki konsep diri positif. Sementara itu, sebanyak 55,7 persen ibu dari keluarga utuh memiliki konsep diri negatif. Sebagian besar ibu keluarga cerai $(96,2 \%)$ dan keluarga utuh $(98,7 \%)$ memiliki konsep diri positif pada dimensi spiritual. Persentase tertinggi $(63,3 \%)$ dengan kategori negatif pada ibu keluarga cerai terdapat pada dimensi stabilitas emosi. Sabilitas emosi adalah penilaian ibu terhadap kemampuan diri mereka secara emosi untuk merasa tenang, rileks, stabil, dan kemampuan mengelola rasa khawatir. Selanjutnya proporsi terbesar $(70,9 \%)$ dengan kategori negatif pada ibu keluarga utuh terdapat pada dimensi relasi lawan jenis (Tabel 3). Relasi lawan jenis adalah penilaian ibu terhadap seberapa dikenal atau populer dan seberapa mudah dirinya melakukan interaksi dengan teman/kolega/kerabat yang berbeda jenis kelamin dengan dirinya.

Hasil analisis uji beda $t$ menemukan bahwa terdapat perbedaan signifikan $(p \leq 0,01)$ konsep diri ibu pada keluarga cerai dan utuh untuk dimensi kejujuran $(p=0,000)$, akademis $(p=0,002)$, dan stabilitas emosi $(p=0,000)$. Sementara itu, konsep diri ibu pada keluarga cerai dan utuh juga berbeda signifikan $(p \leq 0,05)$ untuk dimensi verbal $(p=0,018)$. Secara rinci, hasil analisis uji beda disajikan pada Tabel 4 .

Tabel 3 Sebaran responden berdasarkan konsep diri ibu pada keluarga cerai dan utuh

\begin{tabular}{|c|c|c|c|c|}
\hline \multirow{2}{*}{ Dimensi } & \multicolumn{2}{|c|}{$\begin{array}{c}\text { Keluarga Cerai } \\
(\%)\end{array}$} & \multicolumn{2}{|c|}{$\begin{array}{l}\text { Keluarga } \\
\text { Utuh (\%) }\end{array}$} \\
\hline & + & - & + & - \\
\hline Matematika & 48,1 & 51,9 & 39,2 & 60,8 \\
\hline Spiritual & 96,2 & 3,8 & 98,7 & 1,3 \\
\hline Kejujuran & 63,3 & 36,7 & 41,8 & 58,2 \\
\hline $\begin{array}{l}\text { Relasi lawan } \\
\text { jenis }\end{array}$ & 39,2 & 60,8 & 29,1 & 70,9 \\
\hline Akademis & 91,1 & 8,9 & 79.7 & 20,3 \\
\hline $\begin{array}{l}\text { Pemecahan } \\
\text { masalah }\end{array}$ & 65,8 & 34,2 & 58,2 & 41,8 \\
\hline Kemampuan fisik & K $\quad 39,2$ & 60,8 & 44,3 & 55,7 \\
\hline $\begin{array}{l}\text { Penilaian } \\
\text { keseluruhan diri }\end{array}$ & 83,5 & 16,5 & 78,5 & 21,5 \\
\hline Verbal & 67,1 & 32,9 & 49,4 & 50,6 \\
\hline Stabilitas emosi & 36,7 & 63,3 & 67,1 & 32,9 \\
\hline Relasi orang tua & 82,3 & 17,7 & 89.9 & 10,1 \\
\hline Penampilan fisik & 32,9 & 67,1 & 40,5 & 59,5 \\
\hline $\begin{array}{l}\text { Relasi teman } \\
\text { sejenis }\end{array}$ & 89,9 & 10,1 & 84,8 & 15,2 \\
\hline Konsep diri total & 53,2 & 46,8 & 44,3 & 55,7 \\
\hline
\end{tabular}

Keterangan: $(+)=$ konsep diri positif; $(-)=$ konsep diri negatif
Tabel 4 Hasil uji beda dimensi konsep diri ibu pada keluarga cerai dan utuh

\begin{tabular}{|c|c|c|c|}
\hline Dimensi & $\begin{array}{c}\text { Keluarga } \\
\text { Cerai }\end{array}$ & $\begin{array}{l}\text { Keluarga } \\
\text { Utuh }\end{array}$ & $p$-value \\
\hline Matematika & 58,65 & 51,45 & 0,063 \\
\hline Spiritual & 2,40 & 90,77 & 0,408 \\
\hline Kejujuran & 68,07 & 55,34 & $0,000^{* *}$ \\
\hline Relasi lawan jenis & 51,05 & 49,92 & 0,804 \\
\hline Akademis & 77,74 & 70,42 & $0,002^{* *}$ \\
\hline $\begin{array}{l}\text { Pemecahan } \\
\text { masalah }\end{array}$ & 68,92 & 63,79 & 0,122 \\
\hline Kemampuan fisik & 57,17 & 61,53 & 0,175 \\
\hline $\begin{array}{l}\text { Penilaian } \\
\text { keseluruhan diri }\end{array}$ & 78,34 & 75,46 & 0,335 \\
\hline Verbal & 67,09 & 55,91 & $0,018^{*}$ \\
\hline Stabilitas emosi & 48,80 & 70,12 & $0,000^{* *}$ \\
\hline Relasi orang tua & 78,69 & 84,92 & $0,030^{*}$ \\
\hline Penampilc & 54, & 5,87 & 0,643 \\
\hline $\begin{array}{l}\text { Relasi teman } \\
\text { sejenis }\end{array}$ & 86,07 & 83,75 & 0,407 \\
\hline Konsep diri total & 61,05 & 59,74 & 0,395 \\
\hline
\end{tabular}

\section{Hubungan Karakteristik Keluarga, Karakteristik Remaja, dan Konsep Diri lbu dengan Konsep Diri Remaja}

Hasil analisis korelasi menunjukkan bahwa konsep diri ibu berhubungan signifikan positif dengan lama pendidikan ibu $(r=0,246, p<0,01)$ dan pendapatan keluarga $(r=0,230, p<0,01)$. Artinya bahwa semakin lama ibu menempuh pendidikan formal, maka konsep dirinya akan semakin baik. Selanjutnya semakin tinggi pendapatan keluarga, maka konsep diri ibu akan semakin baik.

Hasil analisis menemukan bahwa konsep diri remaja berhubungan signifikan positif dengan pendidikan ibu $(r=0,216, \quad p<0,01) \quad$ dan pendapatan keluarga $(r=0,224, p<0,05)$. Hal ini menunjukkan semakin lama pendidikan formal yang ditempuh ibu, maka konsep diri remaja semakin baik. semakin tinggi pendapatan keluarga juga memunjukkan konsep diri remaja yang semakin baik.

Konsep diri remaja juga berhubungan signifikan dengan status pekerjaan ibu $(r=0,189, p<0,05)$. Konsep diri remaja juga semakin baik dengan ibu bekerja. Secara umum, konsep diri remaja berhubungan signifikan dengan konsep diri ibu $(r=0,262, p<0,01)$. Artinya bahwa semakin baik konsep diri ibu, maka konsep diri remaja juga akan semakin baik. Khususnya pada dimensi spiritual, relasi lawan jenis, stabilitas emosi, dan penampilan fisik ibu. hal ini diuga karena ibu adalah pengasuh utama di keluarga. 


\section{Pengaruh Karakteristik Remaja, Karakteristik Keluarga, dan Konsep Diri Ibu terhadap Konsep Diri Remaja}

Pengaruh karakteristik remaja, karakteristik keluarga, dan konsep diri ibu terhadap konsep diri remaja dianalisis dengan menggunakan uji regresi linear berganda dengan variabel bebas yang terdiri atas usia remaja, status perkawinan ibu, usia ibu, pekerjaan ibu, pendapatan keluarga, dan konsep diri ibu. Model yang disusun memiliki koefisien determinasi sebesar 0,169 (Tabel 5). Hasil uji regresi menunjukkan bahwa variabel yang mempengaruhi konsep diri remaja dapat dijelaskan oleh 16,9 persen variabel yang digunakan dalam model, sedangkan 83,1 persen dipengaruhi oleh variabel lain yang tidak ada dalam model. Hasil analisis menunjukkan bahwa konsep diri remaja secara signifikan dipengaruhi oleh konsep diri ibu pada dimensi spiritual $(\beta=0,338 ; \quad p=0,000)$, akademik $(\beta=-0,265 ; p=0,021)$, stabilitas emosi $(\beta=0,276 ; \quad p=0,007)$, dan penampilan fisik $(\beta=0,174 ; p=0,039)$.

Tabel 5 Koefisien regresi untuk menganalisis pengaruh karakteristik remaja, karakteristik keluarga, dan konsep diri ibu terhadap konsep diri remaja

\begin{tabular}{|c|c|c|c|}
\hline Variabel bebas & $\mathrm{B}$ & $\beta$ & Sig. \\
\hline $\begin{array}{l}\text { Status perkawinan } \\
\text { ibu (0:cerai, } 1: \text { :utuh) }\end{array}$ & $-4,621$ & $-0,206$ & 0,068 \\
\hline Usia remaja (tahun) & $-0,487$ & $-0,036$ & 0,713 \\
\hline Usia ibu & 0,096 & 0,051 & 0,537 \\
\hline $\begin{array}{l}\text { Pekerjaan ibu } \\
\text { (0: tidak bekerja, } \\
\text { 1: bekerja) }\end{array}$ & 2,825 & 0,125 & 0,153 \\
\hline $\begin{array}{l}\text { Pendapatan keluarga } \\
\text { (Rp/kapita/bulan) }\end{array}$ & 0,001 & 0,057 & 0,511 \\
\hline Konsep diri ibu: & & & \\
\hline - Matematika & $-0,112$ & $-0,021$ & 0,812 \\
\hline - Spiritual & 2,181 & 0,338 & $0,000^{* *}$ \\
\hline - Kejujuran & $-0,904$ & $-0,158$ & 0,075 \\
\hline - Relasi lawan jenis & 1,051 & 0,158 & 0,060 \\
\hline - Akademik & $-1,264$ & $-0,265$ & $0,021^{*}$ \\
\hline $\begin{array}{l}\text { - Pemecahan } \\
\text { masalah }\end{array}$ & 0,226 & 0,037 & 0,699 \\
\hline - Kemampuan fisik & $-0,096$ & $-0,021$ & 0,792 \\
\hline $\begin{array}{l}\text { - Penilaian } \\
\text { keseluruhan diri }\end{array}$ & $-0,211$ & $-0,032$ & 0,737 \\
\hline - Verbal & 0,852 & 0,136 & 0,168 \\
\hline - Stabilitas emosi & 1,108 & 0,276 & $0,007^{\star *}$ \\
\hline - Relasi orang tua & $-0,027$ & $-0,002$ & 0,980 \\
\hline - Penampilan fisik & 0,685 & 0,174 & $0,039^{*}$ \\
\hline Relasi sejenis & 0,678 & 0,095 & 0,271 \\
\hline & \multicolumn{3}{|c|}{0.000} \\
\hline R Square & \multicolumn{3}{|c|}{0,264} \\
\hline Adjusted $R$ Square & \multicolumn{3}{|c|}{0,169} \\
\hline
\end{tabular}

Keterangan: *signifikan pada $\mathrm{p}<0,10 ;{ }^{* *}$ signifikan pada $p<0,05 ;{ }^{\star \star \star}$ signifikan pada $p<0,01$
Sementara itu, variabel usia remaja, status perkawinan ibu, usia ibu, pekerjaan ibu, dan pendapatan keluarga tidak berpengaruh signifikan terhadap konsep diri remaja.

\section{PEMBAHASAN}

Penelitian ini menemukan bahwa konsep diri remaja pada keluarga cerai cenderung lebih positif dibandingkan dengan remaja pada keluarga utuh. Status perkawinan berpengaruh ketika usia remaja, usia ibu, pekerjaan, dan penghasilan per kapita dimasukkan ke dalam model regresi. Hal ini menunjukkan bahwa konsep diri remaja keluarga cerai cenderung menjadi lebih positif jika dikontrol oleh variabelvariabel tersebut. Artinya, remaja dari keluarga cerai dapat mengembangkan konsep diri yang positif jika kondisi ekonomi keluarga tidak terganggu, yang ditandai dengan ibu tetap bekerja, memiliki penghasilan, dan semakin bertambahnya usia remaja dan juga usia ibu. Hal ini sejalan dengan hasil metaanalisis tentang dampak perceraian yang dilakukan oleh Amato (1994) pada anak berbeda-beda tergantung usia anak dan lama perceraian. Bertambahnya usia ibu dan remaja menunjukkan semakin matangnya ibu maupun remaja dalam mengatasi dampak negatif perceraian.

Remaja keluarga cerai dalam penelitian ini ratarata orang tuanya telah mengalami perceraian selama 74,26 bulan atau 6,86 tahun. Kemungkinan besar mereka sudah melewati masa-masa krisis yang ditimbulkan akibat perceraian orang tua. Menurut Demo dan Acock, (1988) remaja yang telah melewati perceraian orang tuanya selama tiga tahun, kemungkinan besar sudah melakukan adaptasi terhadap situasi pasca perceraian dengan baik. Sehingga kondisi keluarga sudah lebih stabil dibandingkan kondisi sebelum dan pada saat mengalami perceraian. Penelitian lain tentang persepsi remaja terhadap perceraian orang tua, menyatakan bisa positif atau negatif (Majzub \& Mansor, 2012), tergantung konflik yang dialami pasca perceraian, kesulitan ekonomi keluarga, tingkat stres yang dialami oleh ibu dan kualitas hubungan ibu dan remaja (Esmaeili \& Yacoob, 2012).

Hasil uji hubungan memperlihatkan bahwa konsep diri remaja semakin positif dengan semakin positifnya konsep diri ibu. Khususnya pada dimensi spiritual, relasi lawan jenis, stabilitas emosi, dan penampilan fisik ibu. Hal ini sejalan dengan pernyataan Coopersmith yang diacu dalam Kaur et al. (2009) yang menemukan bahwa anak-anak dengan konsep 
diri tinggi (positif) berasal dari keluarga yang orang tuanya juga memiliki konsep diri positif, dan memperlakukan anak sebagai individu yang memiliki tanggung jawab. Namun dalam hal persepsi komunikasi, Flora (1975) menemukan hasil yang berbeda bahwa dalam persepsi komunikasi dengan orang tua, konsep diri ibu tidak berpengaruh terhadap konsep diri anak laki-laki maupun perempuan.

Konsep diri ibu adalah penilaian subyektif ibu mengenai dirinya. Hasil analisis pada konsep diri ibu dimensi spiritual, akademis, relasi lawan jenis, stabilitas emosi, dan penampilan fisik memperlihatkan pengaruh yang signifikan terhadap konsep diri remaja. Hanya saja pada dimensi akademik menunjukkan pengaruh yang negatif. Konsep diri ibu dimensi akademik adalah gambaran evaluasi ibu tentang kemampuan akademisnya, apabila hasil evaluasinya rendah artinya ibu memiliki konsep diri dimensi akademik yang rendah atau negatif, dan begitu juga berlaku sebaliknya.

Ibu yang memiliki gambaran evaluasi tinggi pada kemampuan akademiknya cenderung memiliki standar yang tinggi pula terhadap hasil pencapaian akademik anak-anaknya. Sebagian anak mungkin bisa mencapai standar tersebut, tetapi sebagian lagi mungkin memiliki prestasi rata-rata atau bahkan rendah. Standar yang tinggi terhadap ekspektasi pencapaian akademik anak jika tidak diimbangi dengan kemampuan akademik anak dapat memberikan parental pressure pada anak, sehingga dapat memberikan dampak negatif terhadap konsep diri remaja (Leung et al., 2004: Riley, 2003), dan academic pressure (Rogers et al., 2009; Rao, 2008), yang dapat menimbulkan kecemasan dan perasaan tertekan pada remaja. Hal ini dikuatkan oleh penelitian yang dilakukan oleh Pehlivan dan Koseaglu (2012), hasil penelitiannya menemukan bahwa pendidikan dan status pekerjaan ibu maupun ayah tidak memberikan pengaruh positif pada konsep diri akademik remaja.

Penelitian lainnya menyatakan bahwa pada periode transisi remaja, persepsi harapan ibu terhadap kompetensi (maternal competence perceive) meningkat, hal ini dapat menurunkan konsep diri akademik remaja (Gniewosz, Eccles, \& Noack, 2011). Karena remaja merasa terlalu dituntut dan merasa kemampuannya tidak dihargai.

Dimensi konsep diri spiritual meliputi tinggi atau rendahnya pandangan seseorang mengenai aspek-aspek multidimensi dari konsep diri termasuk minat dan reaksi-reaksi emosi positif dan negatif (Meltivier, 2009). Dimensi konsep diri spiritual dan stabilitas emosi memiliki hubungan yang saling menguatkan. Web (2008) dalam penelitiannya tentang religious coping dalam proses adaptasi perceraian, Web menemukan bahwa ibu yang memiliki dimensi spiritual yang tinggi umumnya memiliki emosi yang lebih stabil dan cenderung lebih tenang ketika menghadapi suatu masalah. Religious coping berhubungan dengan penilaian positif terhadap perceraian, rendahnya depresi, dan bertambahnya religiusitas. Menurut Bagley dan Mallick (1997) tingkat religiusitas berhubungan dengan penguatan self esteem. Sedangkan self esteem merupakan komponen penting dalam konsep diri (Marsh, 1992; Hadley, Nair, \& Moore, 2008).

Peran religious coping dan rendahnya depresi memungkinkan ibu tetap mampu memberikan pengasuhan yang baik melalui interaksi positif, dan terhindar dari penerapan pengasuhan yang stres yang ditandai dengan tingginya emosi negatif yang berhubungan dengan rendahnya konsep diri remaja. Sejalan dengan hasil penelitian Asilah dan Hastuti (2014) yang menemukan bahwa pengasuhan afeksi berhubungan positif dengan konsep diri remaja. Ketika ibu dalam kondisi stres, cenderung akan menghasilkan perilaku dan gaya pengasuhan yang negatif serta interaksi yang berorientasi pada kurangnya penerimaan (Ostberg \& Hagekull, 2000). Hal ini dapat menimbulkan tekanan pada konsep diri remaja (Putnick et al., 2008), dan tingkat self esteem yang rendah (Ajilchi et al., 2012).

Sebaliknya, pada penelitian lain ditemukan ibu yang memiliki keterlibatan tinggi dengan kegiatan religiusitas memiliki self esteem lebih tinggi dan skor depresi yang rendah, potensi kekerasan pada anak yang juga rendah, serta lebih memiliki pekerjaan dan pencapaian pendidikan yang tinggi dibandingkan ibu dengan religius yang rendah (Carothers et al., 2005). Hasil penelitian tersebut juga menemukan bahwa, anak-anak dari ibu yang religius lebih sedikit memperlihatkan perilaku negatif, religiusitas meningkatkan dukungan sosial yang berfungsi sebagai faktor proteksi bagi ibu dan remaja.

Hasil analisis pada dimensi relasi lawan jenis ibu menunjukkan pengaruh positif terhadap konsep diri remaja. Dimensi relasi lawan jenis adalah pandangan dan penilaian positif atau negatif ibu mengenai relasinya terhadap lawan jenis (Marsh, 1992). Ibu yang memiliki relasi positif terhadap lawan jenis cenderung memiliki anak remaja dengan konsep diri yang lebih 
positif. Sebagian besar ibu keluarga cerai dalam penelitian ini adalah ibu bekerja, yang memiliki kemungkinan interaksi dengan lawan jenis yang lebih sering dibandingkan dengan ibu keluarga utuh yang sebagian besar tidak bekerja. Ibu yang memiliki relasi atau hubungan yang baik dengan mantan suami, kakek, paman, dan keluarga lain yang lawan jenis memiliki pengaruh positif terhadap konsep diri remaja.

Pentingnya peran relasi lawan jenis pada anak ditegaskan oleh Finley dan Scwartz (2007) yang menemukan bahwa keterlibatan ayah berhubungan dengan kebahagiaan subyektif bagi anak-anak dari keluarga utuh. Sebaliknya, ketiadaan peran ayah bagi anak-anak keluarga cerai menimbulkan rasa "ketidakberuntungan" dan "kehampaan emosi" (emotional longing), yang dapat memunculkan harapan yang tinggi akan keterlibatan ayah. Pada anak perempuan keinginan akan keterlibatan ayah tersebut melebihi ekspektasi dari yang mereka pernah terima sebelumnya. Beberapa ahli menamakan kondisi tersebut sebagai "father hunger" yaitu suatu kondisi kehilangan figur maskulin (a man's deep longing) yang dialami oleh seorang anak (Olson, 2008).

Di sisi lain, sebenarnya hilang atau berkurangnya kontak ibu dengan lawan jenis dalam hal ini ayah atau figur pengasuh lawan jenis membuat anak laki-laki kehilangan kontrol atas perilaku dan contoh peran yang berasal dari figur lawan jenis ibu atau yang sama gender dengan dirinya. Hal ini akan berdampak pada terhambatnya pencapaian berbagai aspek perkembangan sosial remaja, karena kehadiran ayah memainkan peranan yang penting dalam pencapaian kehidupan jangka panjang anak (Finley \& Scwartz, 2007). Sebaliknya, penelitian lain menemukan setidaknya terdapat hal positif dari kondisi ibu keluarga cerai yang menjadi single parent, yaitu ketidakhadiran ayah memungkinkan remaja terhindar dari tekanantekanan yang berasal dari tuntutan ayah, lebih memiliki kesempatan untuk memperluas kemampuan dalam urusan pekerjaan domestik yang biasanya dilakukan ayah sebagai pengganti absennya ayah di rumah (Demo \& Acock, 1988). Temuan Lunberg et al. (2006) menyatakan bahwa dalam pengasuhan, kehadiran anak laki-laki lebih mampu mempertahankan keterlibatan ayah dibandingkan dengan anak perempuan. Ayah lebih terdorong untuk lebih produktif terlibat dalam pengasuhan ketika anak pertama mereka laki-laki.

Usia remaja identik dengan perubahan fisik sebagai konsekuensi masa pubertas. Pada periode ini remaja cenderung lebih sensitif terhadap kritik dan penilaian orang lain terhadap bentuk tubuh (Gupta, 2011). Terutama komentar negatif tentang bentuk dan ukuran tubuh yang berasal dari orang tua (Rice, Larkin, \& Jette, 2001). Kepuasan terhadap bentuk tubuh berhubungan dengan self esteem (Gupta, 2011; Itani, 2011). Orang tua yang memiliki dimensi konsep diri penampilan fisik positif cenderung menunjukkan sikap positif pada kebutuhan remaja terhadap penampilan diri secara fisik agar bisa "fit in" dengan norma kelompoknya, terutama kelompok yang berasal dari teman-teman sebaya (Gentry \& Campbell, 2002).

\section{SIMPULAN DAN SARAN}

Konsep diri antara ibu dari keluarga cerai dan keluarga utuh tidak berbeda signifikan. Konsep diri ibu semakin positif dengan meningkatnya pendidikan ibu dan juga pendapatan keluarga. Konsep diri remaja dari keluarga cerai dan keluarga utuh juga tidak berbeda, namun pada dimensi-dimensi tertentu, yaitu dimensi matematika, penilaian keseluruhan diri, kemampuan fisik, dan verbal pada remaja yang berasal dari keluarga cerai cenderung lebih negatif. Konsep diri remaja semakin positif dengan pertambahan lama pendidikan ibu, besar pendapatan keluarga, dan meningkat juga pada keluarga dengan ibu bekerja. Konsep diri remaja dipengaruhi oleh konsep diri ibu pada dimensi spiritual, akademik, stabilitas emosi, dan penampilan fisik.

Berdasarkan temuan, penelitian ini menyarankan untuk meningkatkan konsep diri ibu sebagai upaya untuk meningkatkan konsep diri remaja. Adapun dimensi-dimensi yang perlu ditingkatkan pada ibu agar dapat meningkatkan perkembangan konsep diri remaja adalah dimensi spiritual, akademik, stabilitas emosi, dan penampilan fisik ibu.

\section{DAFTAR PUSTAKA}

Amato, P. R. (2000). The consequences of divorces for adults and children. Journal of Married and The Family, 62. 12691287.

Ajilchi, B., Kargar, F. R., \& Ghoreishi, M. K. (2012). Relationship between the parenting styles of overstressed mothers with their-esteem. World Conference on Psychology and Sociology 2012. Procedia-Social and Behavioral Sciences 82. 496-5011877-0428. Published by Elsevier Ltd.

Asilah, Hastuti, D. (2014). Hubungan tingkat stress ibu dan pengasuhan penerimaan- 
penolakan dengan konsep diri remaja pada keluarga bercerai. Jurnal IImu Keluarga dan Konsumen, 7 (1), 10-18.

Barber, B. L., \& Eccles, J. S. (1992). Longterm influence of divorce and single parenting on adolescent family and workrelated values, behaviors, and aspirations. Psychology Buletin, 111(1), 108-126.

[BPS] Badan Pusat Statistik. (2012). Kota Bogor dalam Angka 2011. Bogor, ID: Badan Pusat statistik Kota Bogor.

Bagley, C., \& Mallick, K. (1997). Self-Esteem and Religiosity: Comparison of 13- to 15 year old Students in Catholic and Public Junior High Schools. Canadian Journal Of Education, 22(1), 89-92.

Carothers, S. S., Borkowski, J. G., Burke, J. L., \& Whitman, T. L. (2005). religiosity and the socioemotional adjusment of mothers and their children. Journal of Family Psychology, 19(2), Jun 2005, 263275.

Craven, RG. Marsh, HW.2008. The centrality of the self-concept construct for psychological wellbeing and unlocking human potential: Implications for child and educational psychologists. Educational \& Child Psychology Vol 25 No 2. The British Psychological Society.

Demo, D. H. \& Acock, A. C. (1988). The impact of divorce on children. Journal of Marriage and the Family, 50, 619-648. Made available courtesy of WileyBlackwell.

http://www3.interscience.wiley.com.

Devi, R., Anand, S., \& Shekhar, C. (2013) Abuse and neglect as predictors of self concept among below poverty line adolescents from India. Full Length Research Paper. International Journal of Psychology and Counseling, 5(6), 122128. doi: 10.5897/IJPC2013.0213. ISSN 2141-2499@2013 Academic Journals.

Esmaeili, N. S. \& Yacoob, S. N. (2012). Correlates of Self-esteem among adolescents of divorced Families. Archives Des Sciences, 65(8). ISSN 1661-464X.

Evans, M. D., Kelly, J., \& Wanner, R. A. (2001). Educational attainment of the children of divorce: Australia, 1940-90. Journal of Sociology, 37, 275-297.

Fani, S. \& Kherabadi, A. N. (2011). Personality traits and mental divorce. Procedia -
Social and Behavioural Sciences, 30 (2011) 671-675.

Finley, G. E., \& Schwartz, S. J. (2007). Father Involvement and Long-term Adult outcomes: The Differential Contributions of Divorced and Gender. Family Court Review, 45(4), 573-587.

Flora, R. R. (1975). The Effect of parent and adolescent self concept upon adolescent's perceived communication with parents. (thesis). Oregon State University.

Gniewosz, B., Eccles, J. S, \& Noack, P. (2011) Secondary school transition and the use of different sources of information for the construction of the academic selfconcept. Published by Blackwell Publishing, MA 02148, USA. 10.1111/j.1467-9507.2011.00635.x

Gentry, J. H., \& Campbell, M. (2002). Developing adolescents: $A$ Reference for Professionals. American Psychological Association, NE Washington, DC. 200024242

Gupta, C. (2011). The relation between body image satisfaction and self-esteem to academic behaviour in adolescents and pre-adolescents (thesis). University of Manitoba.

Hurlock, E. B. (1980). Psikologi Perkembangan Edisi ke-5. Istiwidayanti, Soedjarwo penerjemah; Jakarta, ID: Erlangga. Terjemahan dari: Developmental Psychology.

Hadley, A. M, Hair, E. C., \& Moore, K. A. (2008). Assesing what kids think about themselves: A guide to adolescent selfconcept for out of school time program practitioners. Child Trend Brief Research to Result.

Hamid, S. R. A., \& Salleh, S. (2013). Exploring single parenting process in Malaysia: Issues and coping strategies. Procedia Social and Behavioral Sciences, 84, 1154-1159. Published by Elsevier Ltd. doi: 10.1016/j.sbspro.2013.06.718.

Itani, D. (2011). Body image, self-esteem and academic achievement of 8th and 11th grades male and female lebanese students (thesis). Lebanese American University.

Kim, H. S. (2011). Consequences of parental divorce for child development. American Socioligical Review, 76(3), 487-511. 
Kotwal, N. \& Prabhakar, B. (2009). Problems faced by single mothers. Jounal Social Science, 21(3), 197-204.

Kaur, J., Rana, J. S., \& Kaur, R. (2009). Home environment and academic achievement as correlates of self concept among adolescents. Journal of Stud Hom Comm Sei, 3(1), 13-17.

Liu, H. J. (2009). Exploring changes in academic self-concept in ability-grouped english classes. Chang Gung Journal of Humanities and Social Sciences, 2(2), 411-432.

Lunberg S. S., Pabilonia, Ward-Batts, J. (2006) Time allocation of parents and invesment in sons and daughters. Working Paper.

Leung, CWY. Chang, CMB. Lai, BPY.2004. Relations among maternal parenting style, academic competence, and life satisfaction in chinese early adolescents. Journal of Early Adolescence. 24(2)113143. DOI:10.1177/0272431603262678@ 2004 Sage Publications.

Marsh, H. W. (1992). Self Description Questionnaire (SDQ) II A theoritical and empirical basis for the measurement of multiple dimensions of adolescent selfconcept. A test manual and research monograph. Macarthur, New South Wales, Australia: niversity of Western Sydney, Faculty of Education.

Majzub, R. M. \& Mansor, S. (2012). Perception and adjustment of adolescents towards divorce. Procedia - Social and Behavioral Sciences, 46, 3530-3534. 1877-0428. Published by Elsevier Ltd. doi: 10.1016/j.sbspro.2012.06.099

Musick, K. \& Meier, A. (2010). Are both parents always better than one? parental conflict and young adult well-being (Forthcoming In Social Science Research). PWP-CCPR-2008-022. California Center for Population Research. On-Line Working Paper Series.

Ostberg, M., \& Hagekull, K.B. (2000). A structural modeling approach to the understanding of parenting stress. Journal of Clinical Child Psychology, 29, 615-625.
Olson, S. (2008). Father Hunger: Jung's dreams of his father. Jung Society of Atlanta. www.jungatlanta.com.

Pehlivan, H., Koseaglu, P. (2012). An analysis of ankara science high school students" attitudes towards biology and their academic self-concepts in term of some family characteristics. Journal of Social and Behavioral Science, 46. 944-949.

Putnick, P. L., Bornstein, M. H., Hendricks, C., Painter, K. M., \& Suwalsky, J. T. (2008). Parenting behaviour and adolescent self concept in european american families. Journal of Family Psychology, 22(5), 752762.

Pryor, J., \& Rodger, B. (2001). Children in changing families: life after parental separation. Oxford, UK: Blackwell Publishers.

Rakhmat. (2011). Psikologi komunikasi. Bandung, ID: Remaja Rosdakarya.

Rogers, M. A., Theule, J., Ryan, B. A., Adams, G. R., \& Keating, L. (2009). Parental involvement and children's school achievement evidence for mediating processes. Canadian Journal of School Psychology, 24(1), 34-57.

Rao, S. A. (2008). Academic stress and adolescent distress: the experiences of 12th standard students in Chennai, India (dissertation). University of Arizona.

Riley, P. J. (2003). The relationship between parental warmth and parental pressure to achieve with adolescent depression and anxiety in China (thesis). Department of Family Studies.

Rice, C., Larkin, J., \& Jette, M. (2001). Mainstreaming body equity. A Report research prepared for the Elementary Teachers' Federation of Ontario.

Sagone, E., \& Caroli, M. E. (2014). Locus of control and academic self-efficacy in university students: The effects of selfconcepts. Procedia-Social and Behavioral Sciences, 114, 222-228. Published by Elsevier Ltd. Selection and peer-review under responsibility of Academic World Education and Research Center. doi: 10.1016/j.sbspro.2013.12.689. 